\title{
THE HOLDING CAPABILITIES OF DIFFERENT COATING MATERIALS ON XYLANASE AND PHYTASE IN SHRIMP FEED
}

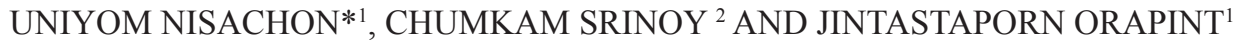

${ }^{1}$ The Department of Aquaculture, Faculty of Fisheries, Kasetsart University, 50 Thanon Ngamwongwan, Lat Yao, Chatuchak, Bangkok 10900. ${ }^{2}$ The Faculty of Agricultural Technology, Valaya Alongkorn Rajabhat University, Pathum Thani, Thailand.

*Corresponding author: nisachon.uni92@gmail.com

Submitted final draft: 5 October $2020 \quad$ Accepted: 17 October 2020

http://doi.org/10.46754/jssm.2021.02.013

\begin{abstract}
An experiment was conducted to discover the amount of enzyme leached by different materials used to coat white shrimp (litopenaeus vannamei) feed to find a solution for the efficient application of enzyme additives in aquaculture feed. Treatments in the study were assigned according to a completely randomized design (CRD). Three materials - chitosan, pullulan, and seal4 - were compared as shrimp feed coatings in terms of their impact on the retention of two enzymes: phytase and xylanase. A sample of feed without coating materials served as the control. Samples were immersed in water, with the levels of enzyme leaching calculated at intervals of 15 and 30 minutes. Feed coated with phytase and pullulan retained the most enzyme, with $32.88 \%$ and $34.45 \%$ leaching after samples were immersed in water for 15 and 30 minutes, respectively. Pullulan was also the most effective in the retention of xylanase, with $0.075 \%$ and $0.078 \%$ leaching after samples were immersed in water for 15 and 30 minutes, respectively.
\end{abstract}

Keywords: Phytase, Xylanase, Chitosan, Pullulan, Seal4.

\section{Introduction}

The aquaculture business has been steadily growing over the past few decades. This is particularly the case with the shrimp industry, which continues to be the most vital aquaculture import and export product in terms of value (Jantarathin et al., 2017). Nevertheless, the industry has recently been experiencing challenges, owing to the limited availability of the main ingredients in shrimp food. The fishmeal market, for instance, has been negatively affected by illegal, unreported and unregulated (IUU) fishing, as well as sky-rocketing prices. As a consequence, most shrimp-feed producers have been forced to develop new formulations, replacing fishmeal with other ingredients, such as soybean meal, worm meal, and algae powder. Plant-based proteins, however, seriously impact aquaculture animals' digestion: soybean meal contains antinutritional factors, for example, phytate, cellulose, and other fibres (Qiu \& Davis, 2016). Hence, this study aims to solve such problems by the addition of common enzymes that break down nutrients from plant proteins in aquafeed: phytase, xylanase cellulose, and protease.
Phytases are a group of enzymes known as myoinositol-hexaphosphate phosphohydrolases. They are used to degrade phytate to sequentially produce myoinositol penta-, tetra-, tri-, di-, and monophosphates, and neutralize the negative effects of phytate on protein and other nutrients in the diets of monogastric animals (Mitchell et al., 1997; Vasudevan et al., 2019). Phytase is produced by microorganisms, and is present in some plant materials. One unit of phytase (FTU) is defined as the quantity of enzyme that liberates 1 micromol of inorganic phosphorus (P) per minute from $0.0015 \mathrm{~mol} / \mathrm{L}$ sodium phytate at $\mathrm{pH} 5.5$ and temperature of $37{ }^{\circ} \mathrm{C}$ (Han, 1989; Walk et al., 2012). Phytase is able to release additional phosphorus by converting phosphorus bonded with phytic acid to available phosphorus. This action leads to improved phosphorus bioavailability, the decreased presence of inorganic $\mathrm{P}$, and the prevention of bonded phosphorus' release as pollution in aquatic environments (Yoo et al., 2005).

Thailand is an agricultural country that produces large quantities of corn, broken rice, sugar cane, etc, which are used as plant ingredients in the feed business. However, the 
cell walls of most plant ingredients comprise three main components, namely: cellulose, hemicellulose, and pectin, with a breakdown of $70-80 \%, 20-30 \%$ and $5-10 \%$, respectively (Li et al., 2013). Hemicellulose constitutes approximately $30 \%$ of a plant's dried weight, with the majority being xylan, a group of betaxylopyranose residues linked by 1,4 glycosidic bonds. The enzyme xylanase plays an important role in the digestion of xylan. Nowadays, xylanase is widely used in the food, drink, and agricultural industries, such as in the production of animal feed with plant-based ingredients (Kawaminami \& Iizuka, 1969; Kumar et al., 2017). It has been established that xylanase can improve plant ingredients' energy release and nutrient availability in poultry and livestock feed (Pirgozliev et al., 2015). However, there is little knowledge about this enzyme's use in, and effect on, aquafeed.

In addition, enzyme supplementation in aquafeed is not a high priority for feed mills at present. The production process for shrimp and fish feed limits such supplementation: the high temperatures required destroy the enzymes in feed materials, and thus enzymes must be mixed with other coating materials for postpelletizing application. Nowadays, feeds are coated with chitosan and other feed additives on farms directly before usage. However, knowledge about coating materials remains very limited. Most experiments focus on the benefits of enzymes without a view on industrial applications. This study sets out to determine the efficiency of different coating materials in terms of the conservation of the xylanase and phytase enzymes by measuring the leaching amount of a given enzyme.

\section{Materials and Methods}

\section{Shrimp Feed Formula}

The majority of the shrimp feed used in this study are made from plant-based ingredients (Table 1). It is commercially available, and is typically used by shrimp farms.
Table 1: The composition of commercial shrimp feed (35\% of protein formula)

\begin{tabular}{|l|l|}
\hline Soybean meal & $35 \%$ \\
\hline Flour & $30 \%$ \\
\hline Fishmeal & $15 \%$ \\
\hline Squid paste & $10 \%$ \\
\hline Premix (Vitamin and mineral) & $5 \%$ \\
\hline Emulsifier and preservative & $4 \%$ \\
\hline Oil & $1 \%$ \\
\hline
\end{tabular}

\section{Experimental Design}

Treatments in this study were assigned by a completely randomized design (CRD). The enzymes phytase or xylanase were applied to a sample of commercial shrimp feed. The control comprised samples of feed coated with phytase or xylanase, and samples without any coating materials. Three further coating materialschitosan, pullulan, and seal4-were applied to enzyme-coated samples, with observations of phytase and xylanase leaching made at intervals of 15 and 30 minutes. Nine replications were conducted for each treatment.

\section{Preparation of Coating Materials}

The coating materials were: chitosan 2\% (Chitomax, Pacco); pullulan 0.015\% (MyskinRecipe); and seal4 0.003\% (Pathway Intermediates Thailand). Each sample of shrimp feed weighed $50 \mathrm{~g}$. A mixture of the given enzyme with $1 \mathrm{ml}$ of a coating material in different treatments was sprayed on top of each sample. The study was divided into four treatments: 1) feed alone (control); 2) feed and chitosan; 3) feed and pullulan; 4) feed and seal4. Two different enzymes, xylanase and phytase, in liquid form (Huvepharma, Thailand) were used in the experiment. After coating, feed samples were then dried for 30 minutes. In order to test the amount of leaching, $10 \mathrm{~g}$ of coated feed was soaked in $30 \mathrm{ml}$ of distilled water. Samples of solutions were taken from each treatment at 15 and 30 minutes. The xylanase concentration measured $1500 \mathrm{EPU}(100 \mathrm{ml} /$ ton of feed); and 
the phytase concentration measured 500 FTU (100 $\mathrm{ml} /$ ton of feed). For the control sample, distilled water was applied instead of coating materials.

\section{Analysis of Enzyme: Xylanase}

To determine the activity of xylanase, xylose was used as a substrate, which, when digested by the enzyme, liberates reducing sugar. The amount of liberated reducing sugar was measured using 3,5-dinitrosalicylic acid (DNS) assays. In brief, the sample solution was added to a substrate of $1 \%$ xylan in a phosphate buffer, at $\mathrm{pH}$ 8. After incubation at room temperature $\left(25^{\circ} \mathrm{C}\right)$, DNS was added, with the mixture subsequently boiled to stop the reaction. The solution was measured for absorbance at $480 \mathrm{~nm}$ using a spectrophotometer. The percentage of xylanase enzyme leaching was calculated from the following Equation 1.

$$
\% \text { Leaching of xylanase }=\frac{\text { initial xylanase enzyme }\left(\frac{\frac{u m o l}{\min }}{\mathrm{g}} \mathrm{feed}\right)-\text { final xylanase enzyme leaching }\left(\frac{\frac{u \text { min }}{\mathrm{min}}}{\mathrm{g}} \mathrm{feed}\right)}{100}
$$

\section{Analysis of Enzyme: Phytase}

To determine the activity of phytase, phytic acid was used as a substrate, which is digested by phytase. In brief, the sample was added to a phytic acid solution in buffer at $\mathrm{pH} 2.5$, then immediately mixed by inversion and incubated at $37^{\circ} \mathrm{C}$ for exactly 30 minutes. Colour-reagent solution was then added, and the absorbance was measured on a spectrophotometer at 400 nm (Heinonen \& Lahti, 1981). The percentage of phytase enzyme leaching was calculated from the following Equation 2.

$$
\% \text { Leaching of phytase }=\frac{\text { initial phytase enzyme }\left(\frac{\frac{u m o l}{\min }}{\mathrm{g}} \text { feed }\right)-\text { final phytase enzyme leaching }\left(\frac{\frac{u m o l}{\min }}{\mathrm{g}} \text { feed }\right)}{100}
$$

\section{Statistical Analysis}

The study used a completely randomized design (CRD). All data were analysed by one-way ANOVA (analysis of variance) with SPSS. Duncan's procedure was used for multiple comparisons of the differences between treatments' means. Alphabetical notation (a, b, c in Tables 2-3) was used to mark differences at a significance level of alpha $0.05(\mathrm{P}$-value $\leq 0.05)$.

\section{Results and Discussion}

\section{Phytase Enzyme Leaching}

The efficiency of different coating materials in terms of preservation of xylanase and phytase added to shrimp feed was studied by comparative measurement of the enzyme-holding ability of three compounds: chitosan, pullulan, and seal4. Figure 1 presents the results, showing the amount of leaching (\%) evident with the various coating materials.

After mixing the phytase enzyme with coating materials and applying this mixture to feed samples, the amount of enzyme leaching was calculated by comparing the amount of enzyme present in the solution after the sample's immersion in water with the amount present after the initial enzyme supplementation. The results presented in Table 1 clearly illustrate that the amount of phytase leaching from the feed coated by chitosan, and from the feed treated with the enzyme without any other coating material, was significantly higher $(\mathrm{P}>0.05)$ than for samples coated with pullulan or seal4. The feed with chitosan coating exhibited no difference from the control sample of feed, which is coated with the phytase enzyme alone. On farms, chitosan is commonly used as a coating post-pelletizing. 


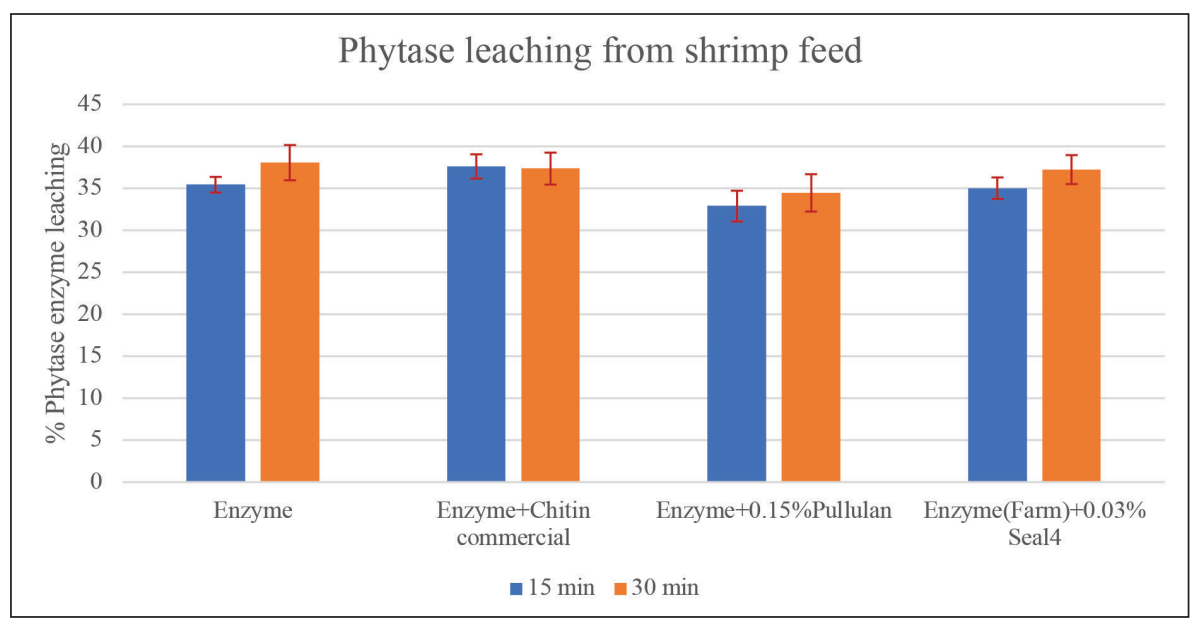

Figure 1: Percentage of phytase leaching from shrimp feed coated by different materials after immersion in water for 15 and 30 minutes

Chitosan is a biodegradable compound, with good film-forming properties, and thus is suitable for use in capsules' external shell with the reaction of anionic polymers as alginate (Kailasapathy \& Chin, 2000). It has been reported that chitosan coating can enhance animals' resistance to environmental stress. Chitosan is acquired from chitin through deacetylation in an alkaline media. In fact, chitosan is a copolymer comprising (1-4)-2-acetamido-D-glucose and (1-4)-2- amino-D- glucose units (Abdou et al., 2007). It shows antimicrobial properties in association with its cationicity and film-forming properties (Domard, A \& Domard, M, 2001). However, feed coated with chitosan is less able to hold enzymes than other materials because it is less sticky, which affects enzymes' dispersion. For this reason, the phytase enzyme may not have been securely attached to the shrimp feed samples, leading to the high figures observed for enzyme leaching.

On the other hand, seal4 held enzymes better than commercial chitosan and those without coating. This could be due to seal4's composition from liquid gum and modified starch, with both being polysaccharide-based raw materials. Such materials are used in many kinds of food products as thickening agents with various applications, for instance: films, hydrogels, microspheres, nanoparticles, and matrix tablets (Jain et al., 2008). Other benefits include biocompatibility and biodegradability (Shalviri et al., 2010). This means that seal4 possesses thickening properties, though as a coating it is still less viscous than chitosan, meaning that it is less able to cover and attach

Table 2: Phytase leaching from shrimp feed coated by different materials after immersion in water for 15 and 30 minutes (mean \pm Standard deviation)

\begin{tabular}{lcc}
\hline Treatments & \multicolumn{2}{c}{ Length of time immersed in water } \\
\cline { 2 - 3 } & $\mathbf{1 5} \mathbf{~} \mathbf{~ i n}$ & $\mathbf{3 0 ~} \mathbf{~ m i n}$ \\
\hline Phytase & $35.4236^{\mathrm{a}} \pm 0.025$ & $38.0533^{\mathrm{a}} \pm 0.032$ \\
Phytase + 2\% chitosan (commercial) & $37.6023^{\mathrm{a}} \pm 0.017$ & $37.3419^{\mathrm{a}} \pm 0.068$ \\
Phytase $+0.15 \%$ pullulan & $32.8827^{\mathrm{c}} \pm 0.019$ & $34.4517^{\mathrm{b}} \pm 0.044$ \\
Phytase $+0.03 \%$ seal4 & $35.0170^{\mathrm{b}} \pm 0.016$ & $37.2275^{\mathrm{a}} \pm 0.046$ \\
\hline
\end{tabular}

Note: The presence of superscript letters a $\mathrm{b} c$ indicates a significant difference $(\mathrm{P}<0.05)$. 
to shrimp feed than chitosan. After 30 minutes' immersion in water, samples coated with seal4 showed the highest amount of phytase leaching.

Pullulan exhibits low viscosity, and thus has greater capacity to cover pelleted feed. Pullulan is obtained from fermentation of the fungus-like yeast Aureobasidium pullulans (Pullularia pullulans). Its structure consists of maltotriose trimer by a-(1,6)-linked and (1,4)- a-D-triglucosides (Farris et al., 2014). Pullulan is routinely used as a coating material these days, thanks to its peculiar properties, for example, its capacity to form a barrier against oxygen and carbon dioxide. However, pullulan was previously well known primarily as an edible coating, applied in a thin layer directly on the surface of the food product (Pavlath \& Orts, 2009). Pullulan performed best in terms of minimising enzyme leaching, which suggests that it is a biopolymer with many interesting, and unexplored, properties. Table 1 clearly shows that, after being immersed in water for 15 and 30 minutes, samples of shrimp feed with phytase and pullulan coatings showed significantly lower percentage of leaching than all other coated samples, with $32.8827 \%$ and $34.4517 \%$ leaching, respectively. However, after being immersed in water for 15 minutes, samples with seal4 coating had lower leaching than samples with chitosan coating. After 30 minutes of immersion in water, there was no significant difference in the amount of phytase leaching from non-coated feed, chitosan-coated feed, and seal4-coated feed. Therefore, pullulan exhibits better efficacy as a coating for shrimp feed than chitosan and seal4.

\section{Xylanase Enzyme Leaching}

Figure 2 presents the results from feed samples coated with xylanase alone, and those coated with the enzyme and one of three coating materials (chitosan, pullulan, and seal4). The amount of xylanase leaching was calculated after the samples were immersed in water for 15 and 30 minutes.

Generally, the amount of enzyme leaching from the feed depended on the quality of the coating material. Table 2 illustrates that feed coated with xylanase and chitosan demonstrated the highest percentage of leaching: chitosan has a lower capacity to hold xylanase enzyme than pullulan and seal4. Each coating's viscosity differs according to the properties of their constituent materials. Less thick coatings seem to attach to enzymes more securely, and disperse over the feed more expansively compared with sticky coating.

Moreover, the results show that chitosan coating released a higher proportion of the

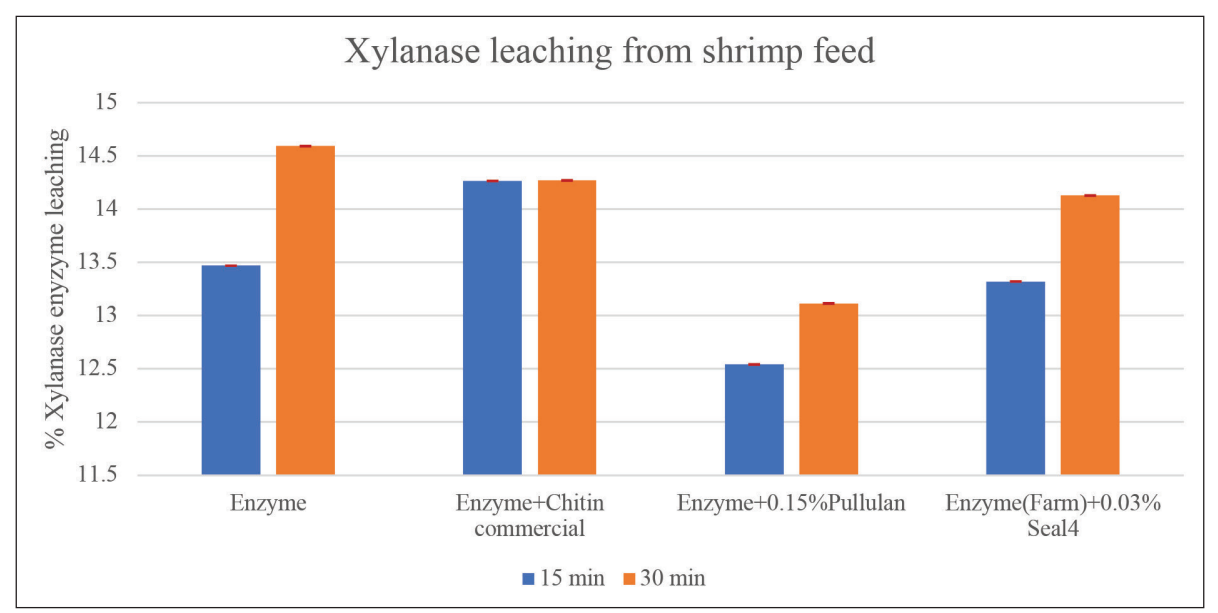

Figure 2: The percentage of xylanase leaching from shrimp feed coated by different materials after immersion in water for 15 and 30 minutes 
Table 3: Xylanase leaching from shrimp feed coated by different materials after immersion in water for 15 and 30 minutes (mean \pm Standard deviation)

\begin{tabular}{lcc}
\hline Treatments & \multicolumn{2}{c}{ Length of time immersed in water } \\
\cline { 2 - 3 } & \multicolumn{1}{c}{$\mathbf{1 5} \mathbf{~} \mathbf{~ i n}$} & $\mathbf{3 0}$ min \\
\hline Xylanase & $13.4693^{\mathrm{b}} \pm 0.002$ & $14.5918^{\mathrm{a}} \pm 0.003$ \\
Xylanase + chitosan (commercial) & $14.2648^{\mathrm{a}} \pm 0.003$ & $14.2697^{\mathrm{a}} \pm 0.004$ \\
Xylanase + 0.15\% pullulan & $12.5417^{\mathrm{c}} \pm 0.004$ & $13.1145^{\mathrm{b}} \pm 0.004$ \\
Xylanase $+0.03 \%$ seal4 & $13.3209^{\mathrm{b}} \pm 0.002$ & $14.1280^{\mathrm{a}} \pm 0.003$ \\
\hline
\end{tabular}

Note: The presence of superscript letters a $\mathrm{b} c$ indicates a significant difference $(\mathrm{P}<0.05)$.

enzyme than other materials. By contrast, the coating with xylanase and pullulan recorded the lowest percentage of enzyme leaching in both immersion periods in water, at 15 and 30 minutes. The results for the xylanase enzyme thus correlated with those of the phytase enzyme. After 15 minutes of immersion, there was a statistically significant difference between the performances of all three coatings, with pullulan exhibiting the least leaching. On the other hand, after 30 minutes of immersion, the pullulan sample had the least leaching by some margin. This is because, as a biopolymer of maltotriose trimer, it coated the feed with a thin film.

\section{Conclusion}

Pullulan demonstrated the highest capability to retain phytase and xylanase compared with other coating materials. Its comparatively low viscosity makes it simpler to blend with the enzymes. Chitosan and seal4 are thicker coating materials with less spreadability than pullulan's fluid coating, which limits the extent to which they cover the feed. Hence, in combined application with enzymes as a shrimp food coating, pullulan resulted in the least enzyme leaching of all tested samples.

\section{Acknowledgements}

The authors would like to thank Huvepharma, Thailand, for their enzymes and Pathway Intermediates (Thailand) for their samples and the knowledge of the commercial coating samples. The authors would also like to extend our thanks to the Nutrition and Aquafeed Laboratory, Department of Aquaculture, Faculty of Fisheries, Kasetsart University, Bangkok, Thailand for its support in this project, and we would like to thank our colleagues of the laboratory for their help in offering the resources in running the program.

\section{References}

Abdou, E. S., Nagy, K. S. A., \& Elsabee, M. Z. (2007). Extraction and characterization of chitin and chitosan from local sources. Bioresource Technology, 99(1), 1359-1367.

Almasi, H., Ghanbarzadeh, B., \& Entezami, A.A. (2010). Physicochemical properties of starch-CMC- nanoclay biodegradable lms. International Journal of Biological Macromolecules, 46(1), 1-5.

Domard, A., \& Domard, M. in: Severian, D. (Ed.) (2001). Chitosan: structure-properties relationship and biomedical applications, Polymeric Biomaterials Marcel Decker Incorporated, New York, 187-212.

Farris, S., Unalan, I., Introzzi, L., FuentesAlventosa, J., \& Cozzolino, C. (2014). Pullulan-based films and coatings for food packaging: Present applications, emerging opportunities, and future challenges. Journal of Applied Polymer Science, 131(13).

Han, Y. (1989). Use of microbial phytase in improving the feed quality of soya bean 
meal. Animal Feed Science and Technology, 24(3-4), 345-350.

Jain, A. K., Khar, R. K., Ahmed, F. J., \& Diwan, P. V. (2008). Effective insulin delivery using starch nanoparticles as a potential trans-nasal mucoadhesive carrier. European Journal of Pharmaceutics and Biopharmaceutics, 69, 426-435.

Jantarathin, S., Borompichaichartkul, C., \& Sanguandeekul, R. (2017). Microencapsulation of probiotic and prebiotic in alginate-chitosan capsules and its effect on viability under heat process in shrimp feeding. Materials Today: Proceedings, 4(5), 6166-6172.

Kailasapathy, K., \& Chin, J. (2000). Survival and therapeutic potential of probiotic organisms with reference to Lactobacillus acidophilus and Bifidobacterium spp.. Immunology and Cell Biology, 78(5), 80-88.

Pavlath, A. E., \& Orts, W. (2009) In Edible Films and Coatings for Food Applications; Embuscado, M. E.; Huber, K. C., Eds.; Springer: New York, Chapter 1, 1. Kawaminami, T. \& Iizuka, $\mathrm{H}$. (1969). Studies on Xylanase from Microorganisms. Agricultural and Biological Chemistry, 33(12), 1787-1789.

Kumar, S., Haq, I., Prakash, J., \& Raj, A., 2017. Improved enzyme properties upon glutaraldehyde cross-linking of alginate entrapped xylanase from Bacillus licheniformis. International Journal of Biological Macromolecules, 98, 24-33.

Li, H., Chen, X., Zhou, J., Han, Y., \& Sun, G. (2013). Etherifying Modification of Xylan-Type Hemicellulose and its Characterization. Advanced Materials Research, 821-822, 1060-1064.

Qiu, X., \& Davis, D. (2016). Effects of dietary phytase supplementation on growth performance and apparent digestibility coefficients of Pacific White Shrimp Litopenaeus vannamei. Aquaculture Nutrition, 23(5), 942-951.

Pirgozliev, V., Rose, S. P., Pellny, T., Amerah, A. M., \& Wickramasinghe, M. (2015) Energy utilization and growth performance of chickens fed novel wheat inbred lines selected for different pentosane levels with and without xylanase supplementation. Poultry Science, 94, 232-239.

Yoo, G., Wang, X., Choi, S., Han, K., Kang, J., $\&$ Bai, S. (2005). Dietary microbial phytase increased the phosphorus digestibility in juvenile Korean rockfish Sebastes schlegeli fed diets containing soybean meal. Aquaculture, 243(1-4), 315-322.

Walk, C., Bedford, M., \& McElroy, A. (2012). Influence of limestone and phytase on broiler performance, gastrointestinal $\mathrm{pH}$, and apparent ileal nutrient digestibility. Poultry Science, 91(6), 1371-1378. doi: 10.3382/ ps.2011-01928. 